\begin{tabular}{|c|c|c|}
\hline 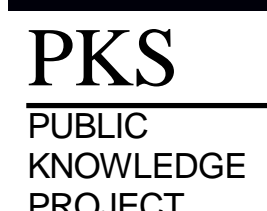 & $\begin{array}{c}\text { REVISTA DE GEOGRAFIA } \\
\text { (RECIFE) } \\
\text { http://nww.revista.uffe. brtrevistageocarafia }\end{array}$ & $\begin{array}{l}\text { OJS } \\
\text { OPEN } \\
\text { JOURNAL } \\
\text { SYSTEMS }\end{array}$ \\
\hline
\end{tabular}

\title{
ANÁLISE EVOLUTIVA DO USO E OCUPAÇÃO DAS TERRAS NAS ILHAS DO MASSANGANO E RODEADOURO, ALTO SUBMÉDIO SÃO FRANCISCO, PETROLINA-PE.
}

\author{
Luiz Henrique de Barros Lyra ${ }^{1}$, Daniel Rodrigues de Lira ${ }^{2}$, Drielly Naama Fonsêca \\ da Silva ${ }^{3}$, Riclaudio Silva Santos ${ }^{4}$
}

\begin{abstract}
${ }^{1}$ Prof. Adjunto do Colegiado em Geografia da Univesridade de Pernambuco, Campus Petrolina. E-mail: barroslyra@bol.com.br

${ }^{2}$ Prof. Adjunto do Departamento de Geografia do Campus Prof. Alberto Carvalho - UFS. E-mail: dniellira@ufs.br

${ }^{3}$ Doutoranda do Programa de Pós-Graduação em Geografia da UFPE. E-mail: driellynaama@gmail.com

${ }^{4}$ Universidade Federal de Sergipe. E-mail: riclaudio.silva@hotmail.com
\end{abstract}

Artigo recebido em 08/10/2017 e aceito em 16/01/2018

\begin{abstract}
RESUMO
A análise do uso e ocupação das terras em bacias hidrográficas são uma das técnicas de gestão e planejamento ambientais mais eficazes para o ordenamento do território e conservação de suas paisagens. Em particular, as ilhas do Massagano e Rodeadouro são unidades geomorfológicas fluviais importantes para o equilíbrio do sistema maior que estão inseridas, no Submédio São Francisco, constituindo indicadores da dinâmica geomórfica da Planície circunjacente pela sedimentação do rio e de outros agentes como escoamentos pluviais, lacustres e eólicos que se refletem numa diversidade de condições de solos, de flora e fauna. Este cenário torna-se um atrativo para múltiplas atividades como a fruticultura, horticultura e o turismo de visitação e lazer. Neste sentido, este trabalho teve como objetivo avaliar a evolução do uso e ocupação das terras nas ilhas entre os anos de 1950, 1998 e 2015, destacando a implantação da Barragem de Sobradinho e do Polo Irrigado na região, e seus impactos ambientais como o desequilíbrio da vazão natural, o desmatamento, a erosão dos solos e o assoreamento do rio. Constatou-se o crescimento das culturas agrícolas que avançaram sobre as áreas de florestas, como também, o aumento da urbanização incipiente e da atividade comercial associada ao turismo.

Palavras-chave: Submédio São Francisco; mudanças ambientais; bacia hidrográfica.
\end{abstract}

\section{EVOLUTIVE ANALYSIS OF THE USE AND OCCUPATION OF LANDS IN THE ISLANDS OF MASSANGANO AND RODEADOURO, HIGH SUBMEDIO SÃO FRANCISCO, PETROLINA-PE}

\begin{abstract}
The analysis of land use and occupation in watersheds is one of the most effective environmental management and planning techniques for spatial planning and conservation of the landscape. In particular, the Massagano and Rodeadouro islands are important fluvial geomorphological units for the balance of the larger system that are inserted in the "submédio São Francisco", constituting indicators of the geomorphic dynamics of the surrounding Plain by the sedimentation of the river and other agents such as storm drainage, lacustrine and wind energy that is reflected in a diversity of soil, flora and fauna conditions. This scenario becomes an attraction for multiple activities such as fruit growing, horticulture and tourism for visitation and leisure. In this sense, this study aimed to evaluate the evolution of land use and occupation in the islands between 1950, 1998 and 2015, highlighting the implementation of the Sobradinho Dam and the Irrigated Pole in the region, and its environmental impacts such as imbalance of natural flow, deforestation, soil erosion and silting of the river. The growth of the
\end{abstract}


agricultural crops that advanced on the forest areas was verified, as well as the increase of incipient urbanization and the commercial activity associated to the tourism.

Keywords: Submédio São Francisco; environmental changes; watershed.

\section{INTRODUÇÃO}

Historicamente a região do Vale do São Francisco, inserida quase que inteiramente na porção Submédia da bacia, foi formada pelo desmembramento da outrora Comarca do Sertão de Pernambuco, em 1820, por ordem da Coroa Portuguesa, dividindo-a em duas e criando a Comarca do Rio São Francisco. Posteriormente, em 1827, grande parte do território pernambucano foi anexada à Província da Bahia, situação que se configura até hoje em embrulho na jurisdição dos dois Estados. Entretanto, a União confere ao Estado de Pernambuco o direito sobre todas as ilhas (terras) do rio São Francisco, além disto, grande parte da população local, e, sobretudo baiana de nascimento, prefere chamar-se de sanfranciscana (GUERRA, 1974).

O território de toda bacia do São Francisco, que em 1968 foi estimado em 640.000 $\mathrm{km}^{2}$, preteritamente teve uma população quantificada por Burton em 1896 de 01 milhão e meio a 02 milhões de almas, chegando em 1939, segundo estatísticas oficiais, a 3.131. 549 habitantes, e em 1974 a cerca de 08 milhões (Op. Cit., 1974). Dados da ANA/GEF/PNUMA/OEA (2003) apresentam uma área total de $638.323 \mathrm{~km}^{2}$ com um contingente populacional de 12.823.013 habitantes, correspondente a uma densidade demográfica média de $20 \mathrm{hab} / \mathrm{km}^{2}$.

Contudo, neste período, quando ainda não tinha sido construída a barragem de Sobradinho, que por sua vez foi concluída em definitivo em 1977, as terras ribeirinhas e das ilhas eram ocupadas de forma incipiente, predominando a vegetação consorciada à pecuária extensiva e a cultura de sequeiro. Um obstáculo para esta ocupação e o uso das terras, além das nuanças climáticas demarcadas pelo rigor nos déficits hídricos com temperaturas elevadas e irregularidade pluviométrica, consistia também na vazão hídrica do rio decorrente dos eventos extremos de cheias e secas. Segundo Pereira e Braz (1993), a barragem, capaz de acumular um volume de 3,4 trilhões de litros de água, não foi projetada para o controle de enchentes e consequentes inundações nas áreas ribeirinhas a jusante, passando a ter esta função somente após a grande cheia de 1979 em que alocou 30\% do seu volume útil com uma descarga de restrição de $8000 \mathrm{~m}^{3} / \mathrm{s}$, reduzindo as cheias associadas a período de recorrência de até 30 anos. 
Estes eventos críticos como as cheias sempre assolaram a região do Submédio São Francisco, como as registradas ainda em meados do Sec. XVI, como as de 1838 e 1865 (RIBEIRO, 2005). Anos mais tarde, já no início do Sec. XX outras cheias igualmente trágicas atingiram a região, sobretudo nas cidades de Juazeiro e Petrolina. Destacam-se as ocorrentes em 1906, 1919, 1925 e 1930, inundando e destruindo edificações principalmente casas e prédios comerciais no centro urbano de Juazeiro (GARCEZ, 1992).

Estudos realizados com dados fluviométricos na bacia do MMA e da Secretaria de Recursos Hídricos (2006) constataram as cheias de 1919, 1925, 1943, 1946, 1949, 1979, 1983, 1992 e 2004 como, até então, as mais importantes registradas. Contudo, foram registrados também alguns eventos de concentração precipitacional de curta duração associados a SC (sistemas convectivos) decorrentes da atuação da Zona de Convergência Intertropical (ZCIT) e Vórtices Ciclônicos de Altos Níveis (VCAN) na região, mas precisamente a jusante da barragem de Sobradinho, como ocorrido no ano de 1984. Neste caso, também houve uma sobrecarga de chuvas a montante que elevou o nível d'água no reservatório afetando o controle das enchentes, provocando inundações nas terras produtivas e prejuízos para à economia regional (NASCIMENTO; CORREIA; GONÇALVES, 2006).

Em relação às secas desde os 500 anos de ocupação do território brasileiro, este fenômeno característico da natureza climática desta região, quando a estiagem se prolonga por mais de quatro anos, assola sua população. Neste cenário, destacam-se as secas de 1889 e 1972, por sua severidade e duração (GUERRA, 1974). As secas na região ocorrem segundo sua intensidade e em uma variabilidade temporal, sendo de dez a onze anos para as mais acentuadas e de cinco a seis anos para as menos intensas (MMA, 2006).

Caviedes (2001), também enfatiza os anos de 1958, 1971, 1983 e 1992, dentre as secas mais prolongadas e severas no nordeste brasileiro, relacionadas aos efeitos do El Niño atuante no Oeste da América do Sul (Quadro 01). SILVA et al. (1999), constatou a relação direta da intensificação dos fenômenos de El Niño em série com a maior parte das secas do semiárido brasileiro, sobretudo na sua parte norte-ocidental, destacando a seca de 1998 que ocasionou um colapso no abastecimento d'água da região, como um acumulo dos déficits hídricos decorrentes de fortes El Niños ocorridos em anos anteriores. 


$\begin{array}{lll}1557-1558^{*} & 1804 & 1951 \\ 1574 * & \mathbf{1 8 0 9 - 1 8 1 0} & 1953 \\ 1583^{*} & 1816 & \mathbf{1 9 5 7 - 1 9 5 8} \\ 1587^{*} & \mathbf{1 8 2 4 - 1 8 2 5} & 1971 \\ 1603 & 1827 & 1983 \\ 1614 & 1830 & \\ 1692 & 1833 & \\ \mathbf{1 7 1 0 - 1 7 1 1} & \mathbf{1 8 4 4 - 1 8 4 5} & \\ 1721 & \mathbf{1 8 7 7 - 1 8 7 9} & \\ \mathbf{1 7 2 3 - 1 7 2 7} & \mathbf{1 8 8 8 - 1 8 8 9} & \\ \mathbf{1 7 3 6 - 1 7 3 7} & 1891 & \\ \mathbf{1 7 4 4 - 1 7 4 5} & 1893 & \\ 1754 & 1900 & \\ 1760 & 1902 & \\ 1772 & 1904 & \\ 1774 & 1907 & \\ \mathbf{1 7 7 7 - 1 7 7 8} & \mathbf{1 9 1 5} & \\ 1784 & \mathbf{1 9 1 9} & \\ \mathbf{1 7 9 0 - 1 7 9 3} & \mathbf{1 9 3 1} & \end{array}$

Quadro 01. Grandes Secas no Nordeste do Brasil entre os anos de 1500 e 2000 (Secas mais prolongadas e severas indicadas em negrito). *Extraído da lista de precipitações anuais em Fortaleza, realizado por Serra em 1973.

Fonte: Caviedes, 2001

A dinâmica ambiental do uso e ocupação das terras nas Ilhas do Massangano e Rodeadouro requer uma análise integrada, pois faz parte de uma unidade sistêmica mais ampla e complexa, a bacia do Alto Submédio São Francisco. Para Guerra e Cunha (2006), as bacias são do ponto de vista natural, social e econômico, unidades integradas do ambiente, ela constitui um sistema aberto onde ocorre entrada de energia fornecida pela atuação do clima e da tectônica locais, eliminando-as pela saída de água, sedimentos e minerais solúveis. Internamente, verificam-se constantes ajustes nos elementos e processos associados, em função das mudanças de entrada e saída de energia. Portanto, mudanças significativas em qualquer elemento da bacia podem gerar alterações e impactos à jusante e nos fluxos energéticos de saída (descarga, carga sólida e dissolvida), assim como, dependendo da amplitude da intervenção, os tipos de leitos e canais também sofrem profundas alterações.

Este recorte hidrográfico em que fazem parte as ilhas, é ocupado por uma população de aproximadamente 600.000 habitantes, impulsionado pela implantação do pólo agrícola irrigado para a produção de frutas, principalmente de uvas de mesa e vinhos onde se instalaram grandes vinícolas que despontaram no cenário nacional e internacional. As plantações se ramificaram nos solos férteis da planície, sobretudo aluviais, se adaptando ao 
rigor climático que condiciona calor e luminosidade suficiente para estimular a frutificação em dois ou três períodos do ano e o manejo da água por técnicas eficientes de irrigação (MALVEZZI, 2009).

Neste cenário, por outro lado, o contraste ambiental acentua-se, sobretudo nos terraços e terras aluviais onde o uso e a ocupação predatória e a consequente degradação da cobertura vegetal, associado à retirada de argila para construção das casas e de outros utensílios domésticos, expôs o solo a um intenso processo erosivo, gerando a desestabilização das encostas, a perda de solos agricultáveis e colmatação da calha fluvial.

Vários trabalhos na região constataram os impactos decorrentes do uso desordenado das terras e a necessidade do disciplinamento deste processo promovendo a proteção da diversidade biológica e a sustentabilidade dos recursos naturais de modo a contribuir com a melhora da qualidade de vida da população local (CÓRDOBA, et. al., 2011; CUNHA et. al., 2011, CUNHA et. al., 2010).

Neste sentido, este trabalho teve como objetivo quantificar e analisar o uso das terras nas ilhas do Massangano e Rodeadouro, durante os anos de 1950, 1998 e 2015, relacionando as intervenções antrópicas na bacia hidrográfica e em particular no Submédio São Francisco, por meio da técnica de classificação e superposição de imagens digitais que procura agrupar pixels com características espectrais similares em classes de Uso da Terra.

\section{MATERIAIS E MÉTODOS}

\section{Localização e Caracterização da Área de Estudo}

As ilhas do Massangano e Rodeadouro, estão inseridas num trecho do rio com altitude média de $355 \mathrm{~m}$ a $371 \mathrm{~m}$, padrão de drenagem predominante dentrítico, canal com morfologia meandrante e anastomasada, leito entrecortado por soleiras, barras e outras ilhas, e margeado por diques, terraços e superfícies alagáveis, típicas de planície de inundação (Figura 01). Segundo Ferreira, Dantas e Shinzato (2014) trata-se da planície Sanfranciscana que está disposta em superfícies sub-horizontais, constituídas de depósitos areno-argilosos, com terrenos deficientemente drenados e sujeitos a inundações periódicas, além de mantos arenosos e campos de dunas situados a sudoeste de Petrolina. Lira (2014) considerou esta planície uma morfoestrutura de origem poligenética com processos agradacionais fluvial, lacustre e eólica. 


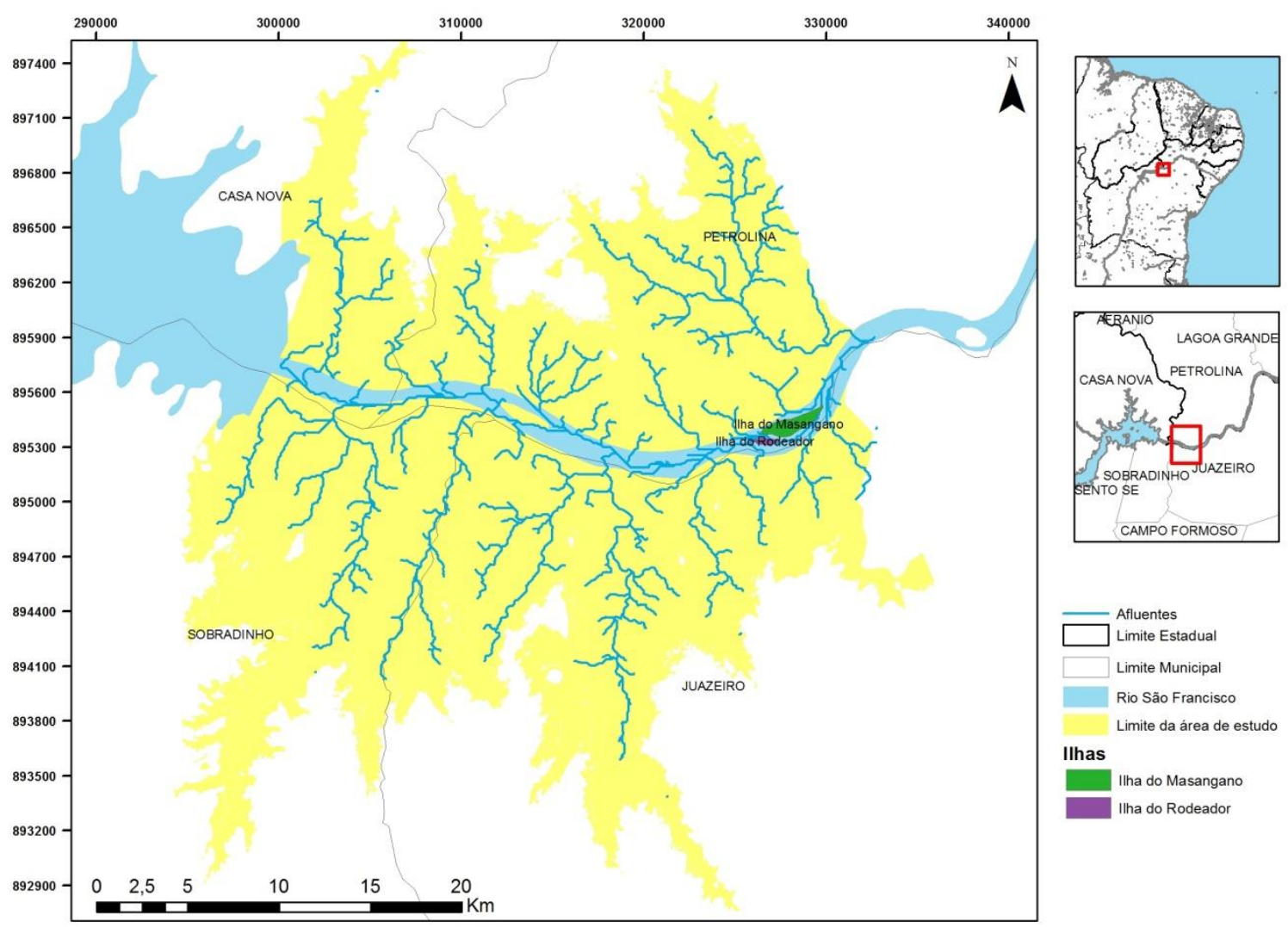

Figura 01. Ilhas no Alto Submédio São Francisco, área de Influência, 2015.

Fonte: organizado pelos autores, IBGE, 2012; SRTM, 2011.

Nesta região, de acordo com o diagnóstico do quadro natural e potencialidades do Semiárido Nordestino (SOUZA et. al., 1996), o clima é do tipo tropical semiárido, os solos são de aluviais associados à planossolos e vertissolos revestidos nativamente por florestas caducifólias de várzea e vegetação riparia (mata ciliar) nas áreas marginais e a caatinga predominante hiperxerófila nas extensa superfície pediplanadas.

O trecho do rio São Francisco em que as ilhas se situam teve sua morfologia alterada em 1977 com a construção da Barragem de Sobradinho a montante e, cerca de dez anos depois, da barragem de Itaparica a jusante. Estas intervenções proporcionarem a regularização do fluxo de água nos períodos de chuvas e as consequentes inundações nas planícies de inundação ao longo de suas margens, como nas cidades de Juazeiro e Petrolina-PE, permitindo a expansão das áreas agricultáveis irrigadas e o uso intenso das terras. Contudo, alterou o nível de base do rio a jusante, com o rebaixamento do canal principal e de seus afluentes e aumentou o aporte de sedimentos, acelerando o assoreamento e a formação de canais entrelaçados com extensas barras longitudinais e ilhotas (SUASSUNA, 2008). 


\section{Mapeamento do Uso das Terras}

Os procedimentos metodológicos adotados foram baseados no processamento e análise de fotografias aéreas e imagens das ilhas nos anos de 1950, 1998 e 2015, Utilizandose a técnica de classificação híbrida, ou seja, tanto supervisionada quanto não supervisionada, por agrupação de pixels com características espectrais similares em classes de Uso da Terra (FLORENZANO, 2008). Os dados foram computados na Plataforma ArcGis e a seleção de temas para a definição de classes segundo o modelo do uso das terras do Classification System Land Cover - LCCS da FAO (GREGORIO, 2005). Técnicas semelhantes, mas com metodologia pré-definidas por supervisionamento em campo, foram utilizadas na mesma região por Córdoba et al (2011); e Cunha et. al. (2011).

Foram utilizadas duas fotografias aéreas das bases da CODEVASF, uma de 1:25000 executada pelo serviço aerofotogramétricos Cruzeiro do Sul S/A em 1950 e outra de 1:12.500 executada pelo Esteio S/A em 1998, e outra imagem de satélite de alta resolução da base do software Google Earth Pro do ano de 2015.

Concomitantemente foram retificadas e analisadas imagens do sensor Landsat 1, 2 e 5 $\mathrm{TM}$, referentes às respectivas órbitas/pontos 233/67 com passagens em 13 de novembro de 1973, e 16 de novembro de 1981; e 217/67 com passagens em 04 de outubro de 1995 e 10 de junho de 2011.

\section{RESULTADOS E DISCUSSÃO}

As imagens de Satélite Landsat do recorte da região adjacente as Ilhas do Massangano e Rodeadouro, dos anos de 1973 e 2011, demonstram a influência direta da barragem na configuração da paisagem, sendo visível a supressão da cobertura vegetal, inclusive nas margens do rio São Francisco e seus afluentes (mata riparia), com o avanço de culturas agrícolas (Figuras 02 e 03). As áreas dos projetos irrigados, sobretudo implantados pelos órgãos públicos executores como a CHESF e a CODEVASF, neste período cresceram rapidamente, com destaque para os anos 1990, se ampliando em todas áreas ribeirinhas de vários tributários de primeira ordem como o rio Salitre, os Riachos do Tatuí, Língua de Vaca e outros a jusante do Salitre todos na margem direita. Na margem esquerda os riachos do Grupo de Bacias de Pequenos Rios Interiores (GI8), em que se destaca o riacho Vitória e mais a montante próximo ao lago de Sobradinho, o riacho do Sobrado.

A vegetação predominante da "mata ciliar" do rio São Francisco se constitui por uma floresta semiaberta, mas com a presença de arbustos, cipós e estrato herbáceo, de extensão 
longa e estreita. Contudo, em decorrência do crescimento agrícola e urbano a maioria desta vegetação se compõe atualmente por remanescentes secundários com estrato predominante arbustivo-arbóreo, destacando-se espécies nativas como a ingazeira (Inga vera subsp. Affinis), o juazeiro (Zizyphus joazeiro) e a carnaubeira (Copernicia cerifera), associada a espécies xerófitas, como a algarobeira (Prosopis juliflora) e gramíneas (NASCIMENTO, 2003).

Segundo o diagnóstico analítico da Bacia do São Francisco e sua Zona Costeira (ANA/ GEF/ PNUMA/OEA, 2003) a região Submédia com $117.351 \mathrm{~km}^{2}$ e uma população de 2.475.322 habitantes, taxa de urbanização de $56 \%$ e antropização de $85 \%$, corresponde a 46,9 \% da área irrigada de toda bacia do São Francisco, o que proporcionou alavancar outras atividades como a agroindústria, geração de energia e mineração, e um relevante índice de desenvolvimento humano - IDH entre 0,438 a 0,664, com destaque para as cidades de Petrolina em Pernambuco e Juazeiro da Bahia. Na mesma proporção deste crescimento, os impactos ambientais para a bacia são alarmantes principalmente pelo desmatamento exacerbado e a exposição dos solos aos processos erosivos com o consequente assoreamento do rio, o que proporcionou uma descarga de 12,9 × $10^{6}$ t/ano de sedimentos em seu leito, equivalente a uma área de $510.800 \mathrm{~km} 2$. 


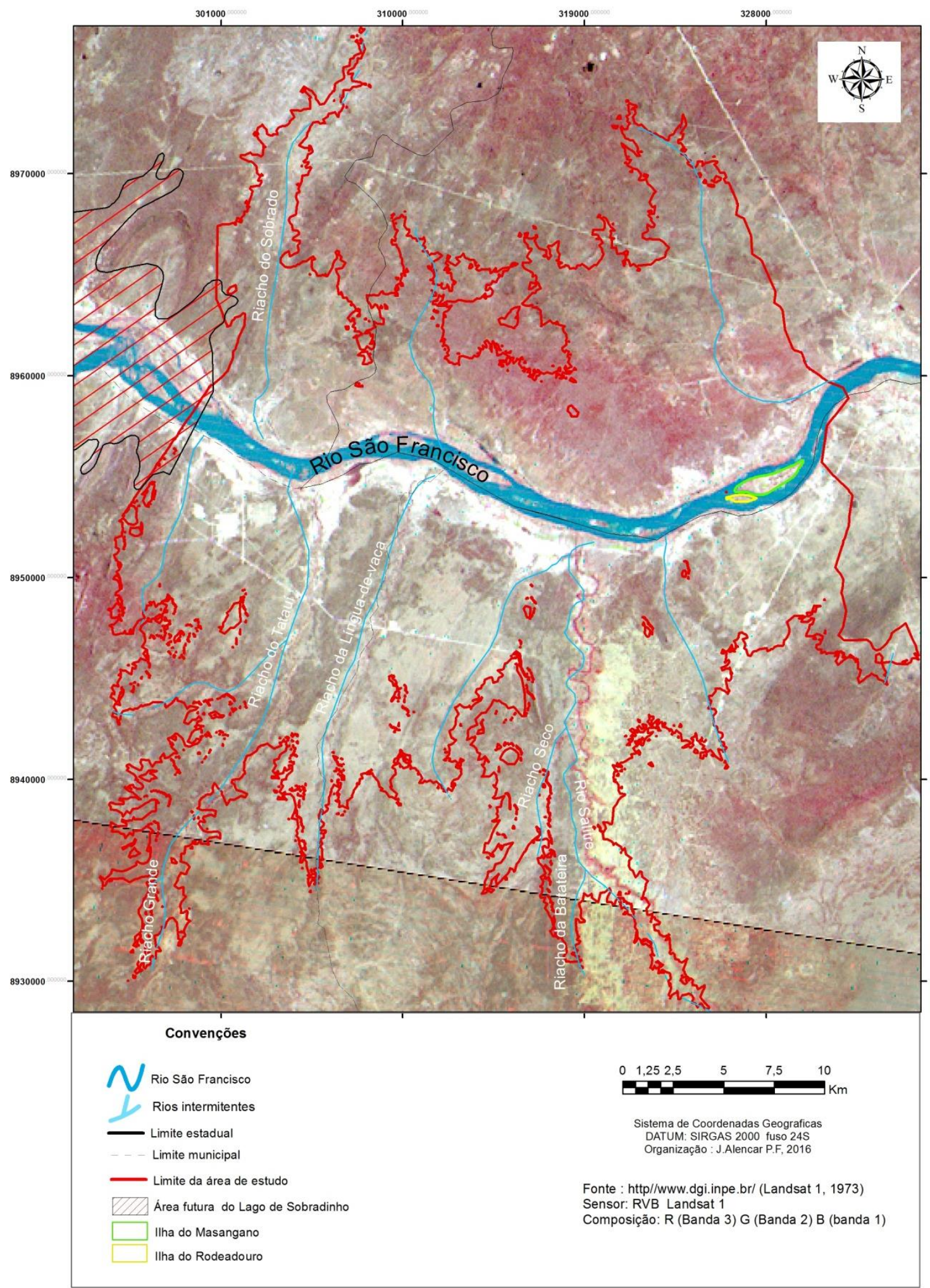

Figura 02. Áreas adjacentes das ilhas do Massangano e Rodeadouro em Recorte do Submédio São Francisco, 1973.

Fonte: INPE, Landsat 1. 


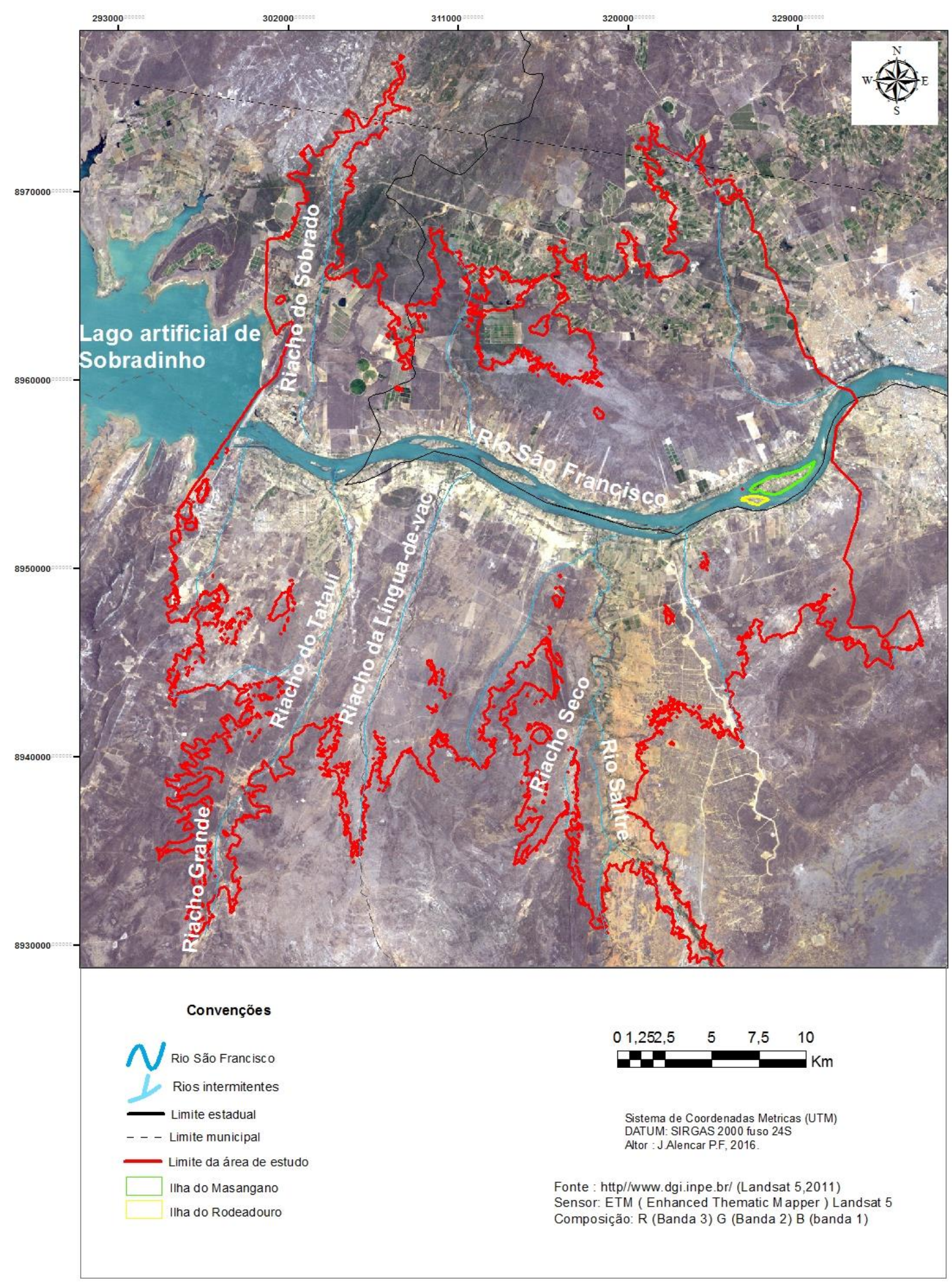

Figura 03. Áreas adjacentes das ilhas do Massangano e Rodeadouro em Recorte do Submédio São Francisco, 2011.

Fonte: INPE, Landsat 5.

As Ilhas do Massangano e Rodeadouro foram ocupadas com pequenas povoações datadas aproximadamente há 200 anos, por volta de 1830, constituídas por índios e negros 
egressos do Sertão de Pernambuco e Bahia (Secretaria Municipal de Educação Petrolina, 2015). Em particular, a Ilha do Massangano, recebeu essa denominação por um antigo fazendeiro de mesmo nome, João do Massangano, pelo qual a família era proprietária da maioria das terras no local.

A partir da década de 1970, com a instalação da barragem de Sobradinho supracitada, estas ilhas como outras terras situadas a jusante, se tornaram um atrativo populacional, pois permaneceram emersas e até se expandiram com a regularização do leito do rio pela vazão controlada durante as cheias, e o cultivo de hortaliças, cebola, mandioca e outros plantios além do período de vazante. Várias famílias que residiam nas áreas ribeirinhas e ilhas próximas do lago represado e da região, posteriormente também inundadas por outras barragens como o lago de Itaparica mais a jusante, vieram residir no lugar por afinidade e acessibilidade hídrica (AQUINO, 2004; OLIVEIRA, 2010).

Segundo o IBGE (2000; 2010), as duas ilhas, com uma área total de 243,3 Hectares $(212,2$ ha na do Massangano e 31,1 ha na do Rodeadouro), abrigavam uma população local aferida por agregação do setor censitário em 2000 de 800 moradores residentes em 198 domicílios, já em 2010 registrou-se 834 moradores residentes em 214 domicílios. Em 2016, de acordo com informações locais de moradores antigos e da prefeitura municipal estima-se que a população local seja em torno de 1000 habitantes.

O perfil desta população se constitui predominante de pescadores, barqueiros e comerciantes, e muitos deles migrantes pendulares que se deslocam semanalmente das cidades de juazeiro e Petrolina para pousar nas ilhas em suas terras com residências para lazer e visitação. Incialmente, agricultores de cebola, arroz e hortaliças, além de criadores de gado, desenvolveram suas atividades nos baixios de vazante. A partir dos anos 90 com a expansão do polo de irrigação Petrolina-Juazeiro, houve o consórcio de uma pequena pecuária semiextensiva com hortaliças e frutas irrigadas, destacando-se a goiaba e o maracujá para subsistência (AQUINO, 2004). Recentemente, se encontra em andamento a implantação de um projeto para o plantio de uvas destinadas à produção de suco integral e vinho colonial na Ilha do Massangano, denominado "Ilha do Vinho", desenvolvido pelas secretarias Executivas de Ciência e Tecnologia e de Irrigação de Petrolina em parceria com a EMBRAPA/Semiárido e o SEBRAE.

A classificação das imagens para o Mapeamento do uso das Terras gerou até sete subclasses correspondentes as feições existentes nas imagens: Culturas Permanentes; Culturas 
Temporárias; Pastagem; Urbanização Incipiente; Urbanização Comercial; Piscicultura; Área Florestal e Área Descoberta.

Análises de fotografias aéreas e imagens das ilhas nos anos de 1950, 1998 e 2015, evidenciam este crescimento em função da implantação dos perímetros irrigados, em particular na planície e áreas ribeirinhas (Figuras 04, 05 e 06). Este cenário evidencia a supressão da cobertura vegetal classificada como área florestal em função do avanço das demais formas de uso e ocupação das terras como principalmente as de culturas agrícolas temporárias e permanentes, urbanização incipiente, e um destaque para as de urbanização comercial na ilha do Rodeadouro devido ao crescimento do turismo de visitação e lazer atraídos pelo banho do rio nas suas margens, com a instalação de bares, restaurantes, chácaras e áreas de camping.

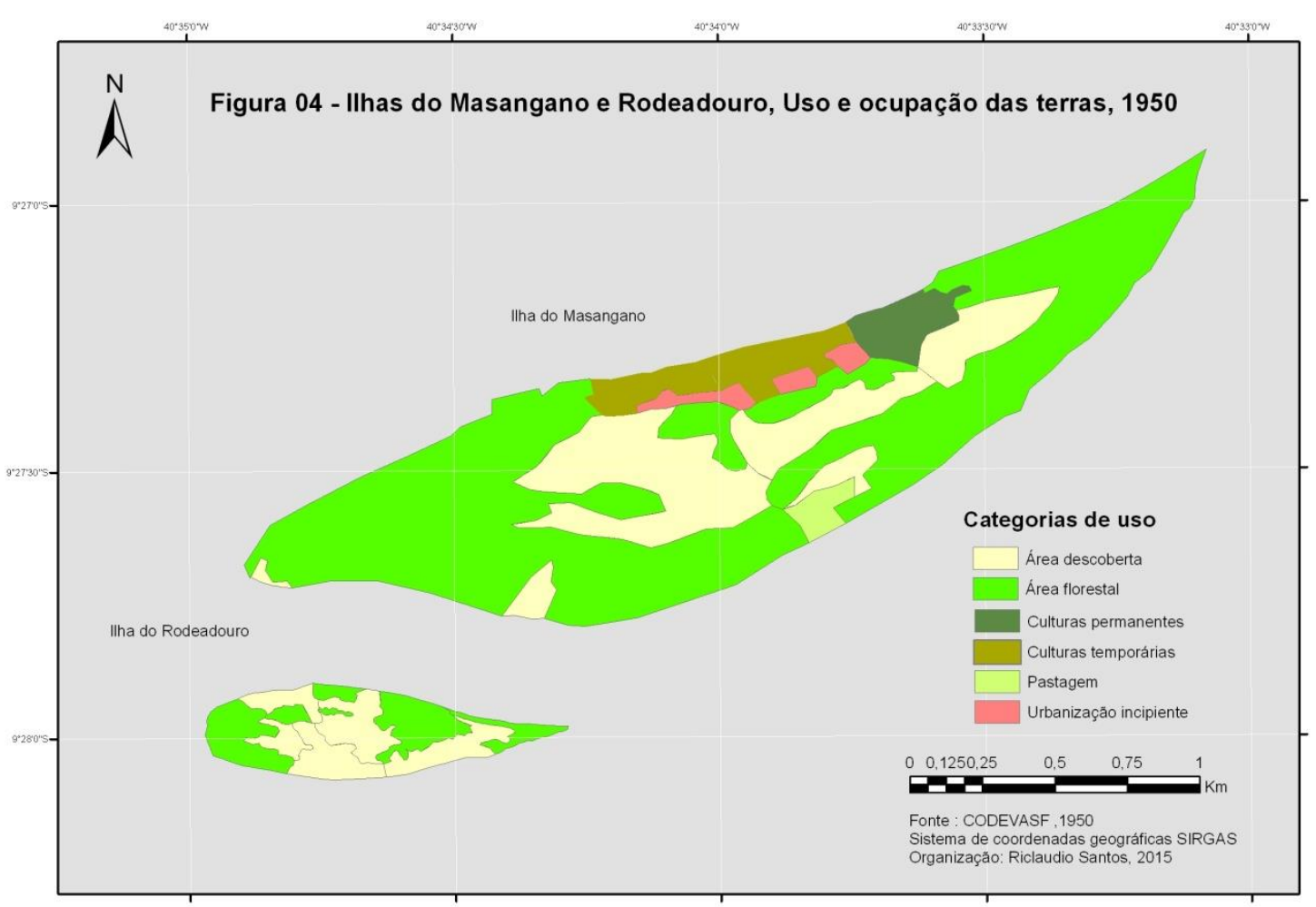

Figura 04. Uso e Ocupação das Terras nas Ilhas do Massangano e Rodeadouro, 1950.

Fonte: Fotografias aéreas CODEVASF. 


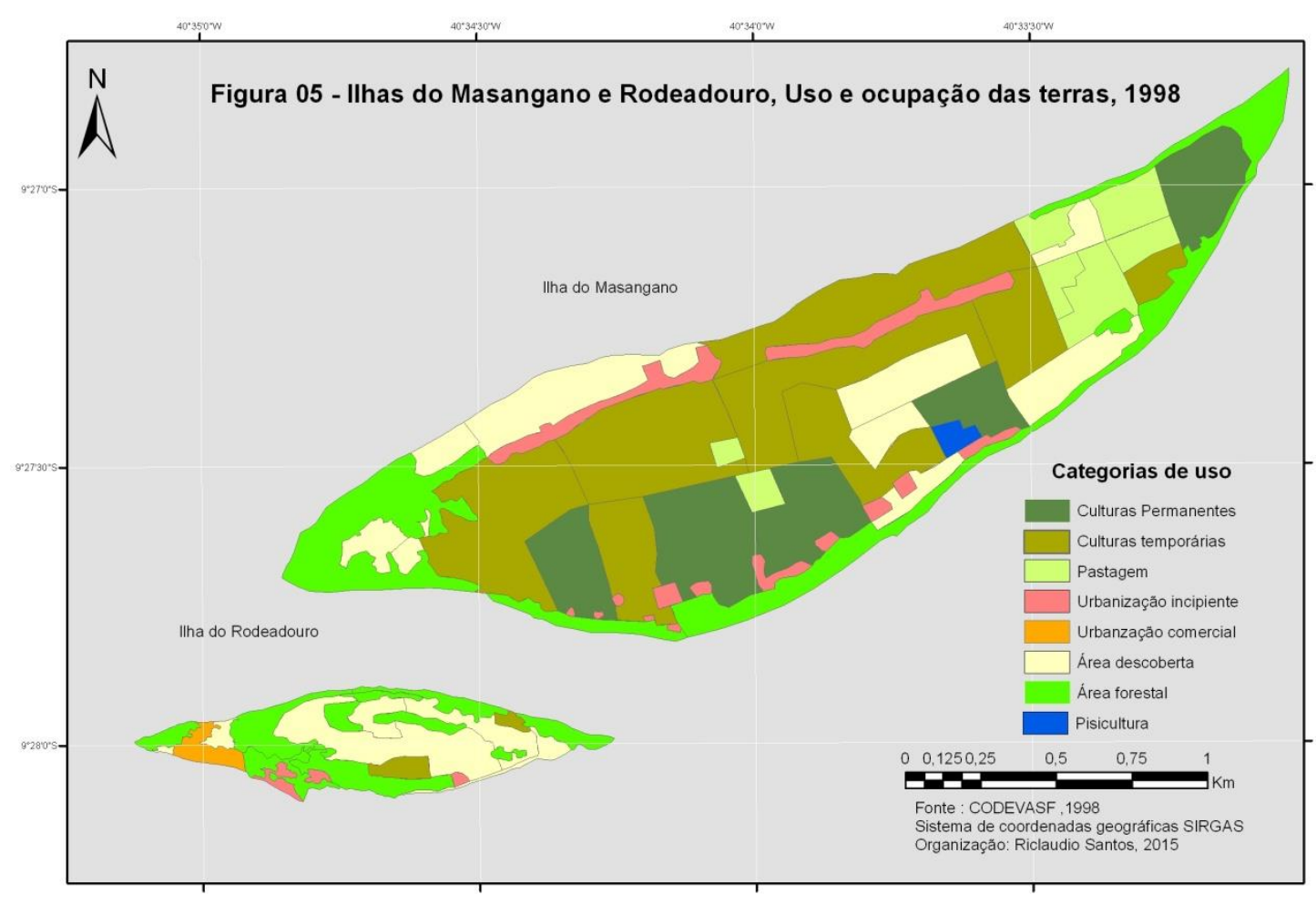

Figura 05. Uso e Ocupação das Terras nas Ilhas do Massangano e Rodeadouro,1998. Fonte: Fotografias aéreas da CODEVASF.

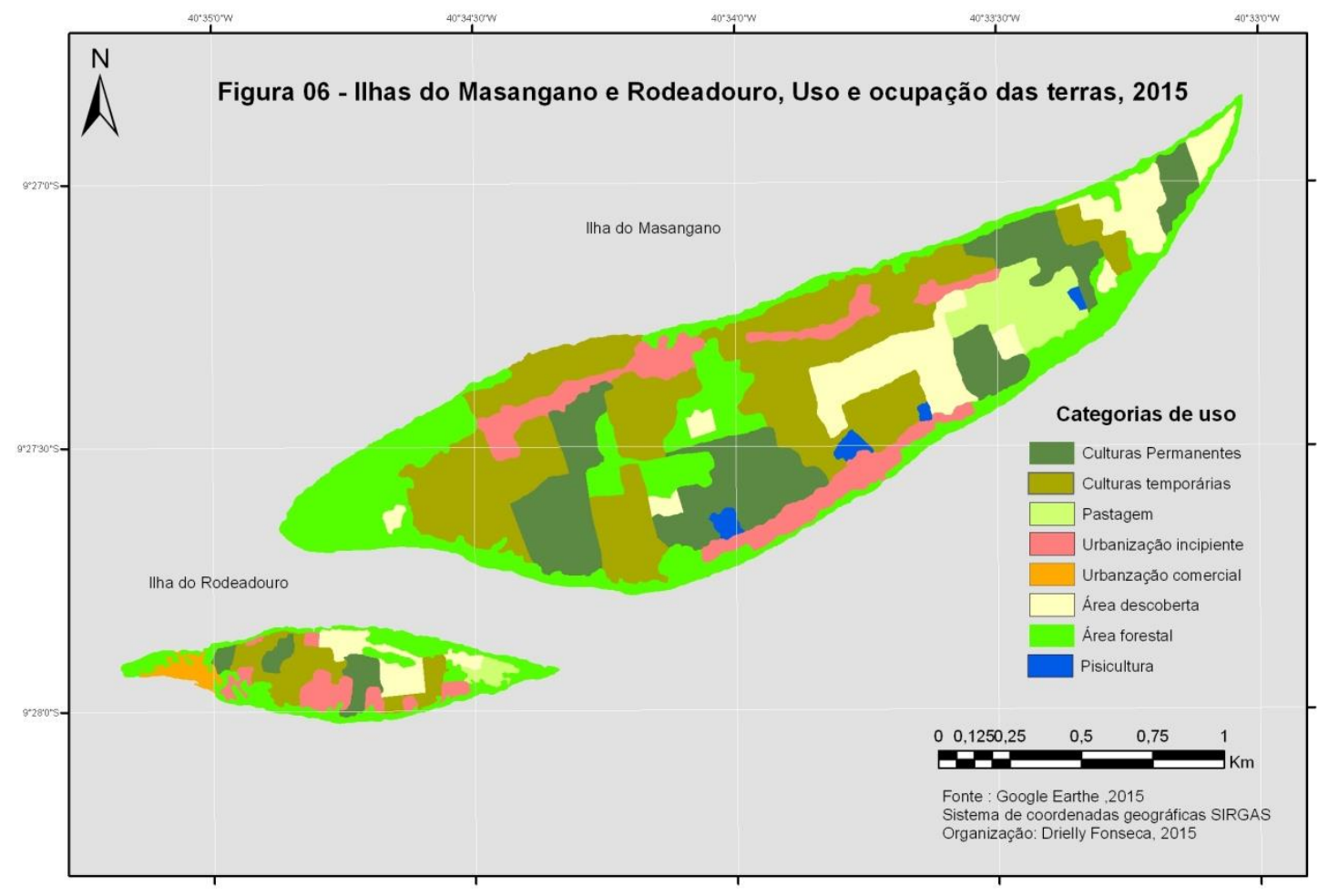

Figura 06. Uso e Ocupação das Terras nas Ilhas do Massangano e Rodeadouro, 2015. Fonte: Imagem Google Earth Pro 2015. 
$\mathrm{Na}$ ilha do Massangano a área florestal que representava 65\% da área total em 1950, passou para apenas 25\% em 2015. Já a área descoberta com 23\% passou para apenas $10 \%$ da área total. Em contrapartida, a área de culturas agrícolas temporárias que compreendiam $6 \%$ da área total em 1950, aumentou para 33\% em 2015. Numa proporção mais reduzida, as culturas permanentes também obtiveram crescimento, passando de 3\% em 1950 para 19\% da área total em 2015. As áreas de pastagem e psicultura são irrelevantes, representando respectivamente $4 \%$ e $1 \%$ da área total no ano de 2015 , inclusive com uma redução de $100 \%$ na primeira em relação ao ano de 1998. Quanto à urbanização só ocorreu de forma incipiente e apesar do aumento significativo continuou representando uma porção muito reduzida da área total da ilha, passando de $2 \%$ para $8 \%$ da mesma (Figura 07).

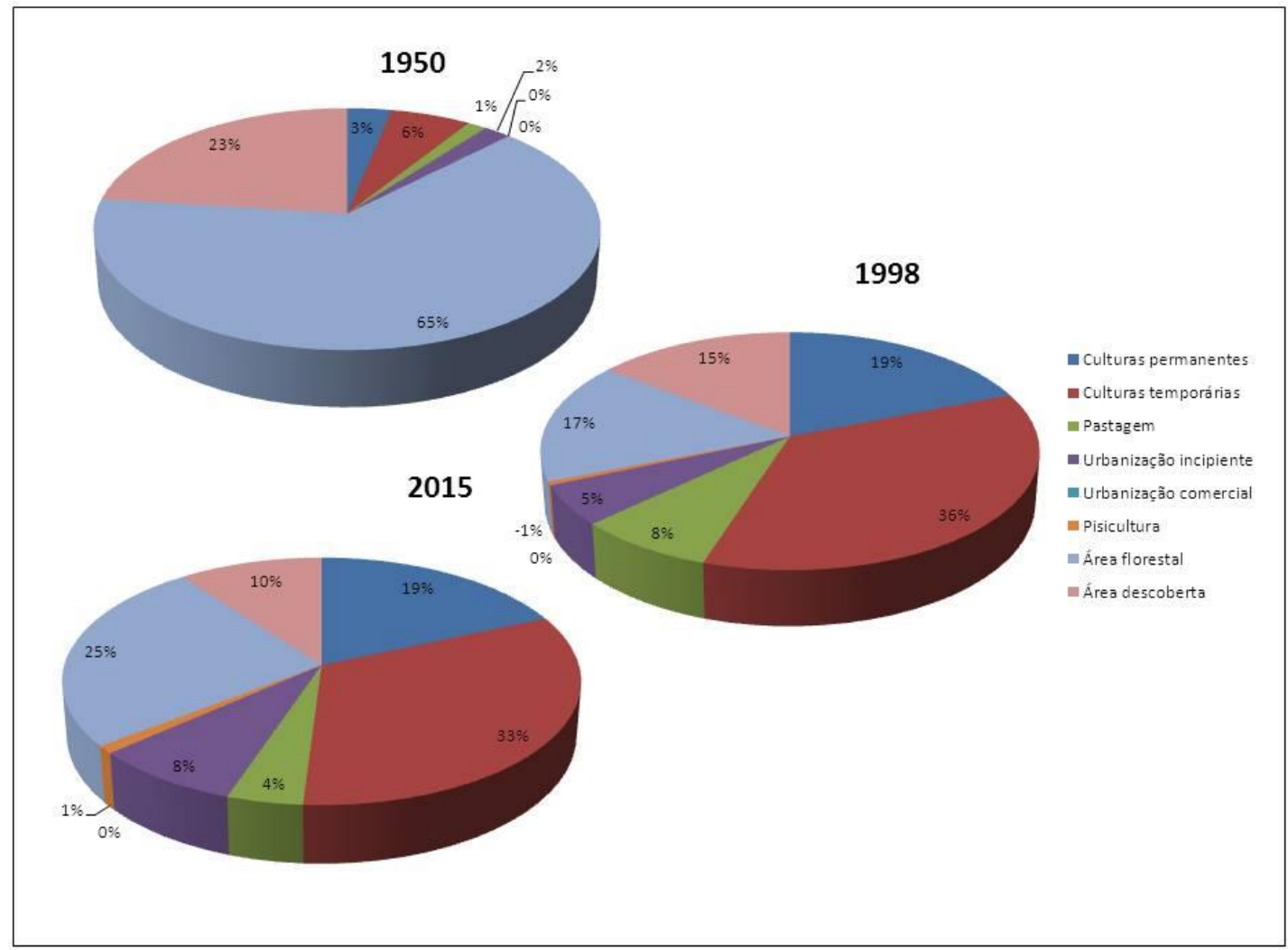

Figura 07. Ilha do Massangano, uso e ocupação das terras (hectares), 1950, 1998 e 2015.

Na ilha do Rodeadouro apesar de ter uma porção ainda significativa de área florestal, que abarca 33\% de sua área total em 2015, houve uma redução considerável de cerca de 30\% em relação ao ano de 1998. A área descoberta reduziu de 55\% da área total no ano de 1950 para apenas 13\% em 2015, dando lugar principalmente para atividades agrícolas com culturas temporárias que no ano de 1998 representava 5,0\% da área total e aumentou para $21 \%$ em 2015, um acréscimo de praticamente $300 \%$ durante o período. Outro destaque que também 
ocorreu no mesmo período foi à urbanização incipiente e comercial, ambas representavam em 1998, respectivamente $4 \%$ e 5\%, aumentando esta proporção para $13 \%$ e $6 \%$ em 2015 . Este aumento, sobretudo da urbanização incipiente se deu pelo fato de muitos pequenos comerciantes e pescadores passarem a residir nas ilhas com o crescimento do turismo de lazer em seu balneário.

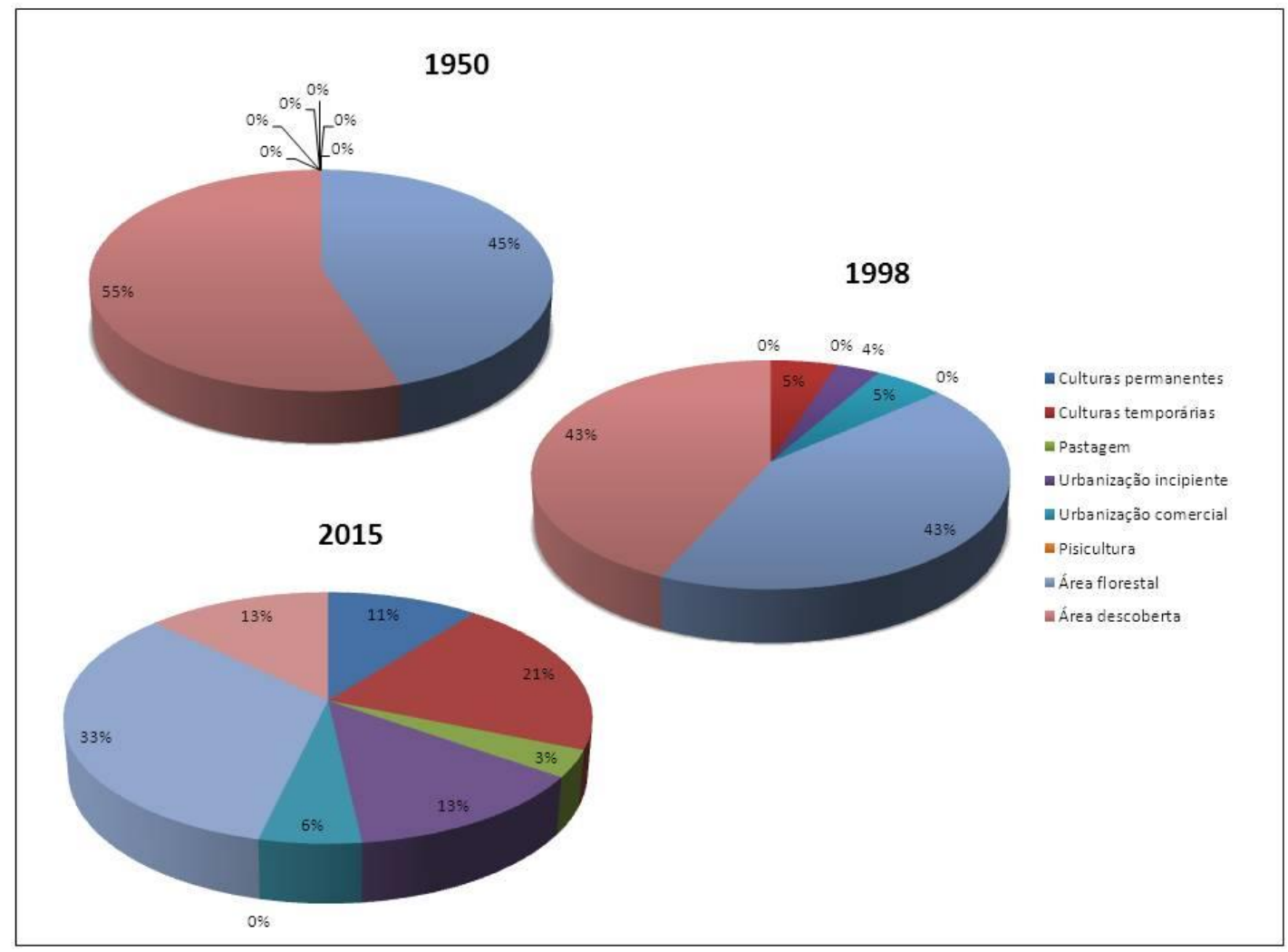

Figura 08. Ilha do Rodeadouro, uso e ocupação das terras (hectares), 1950, 1998 e 2015.

Outro dado importante detectado nas análises das imagens foi à mudança no perímetro total das ilhas, sobretudo na ilha do Massangano entre os anos de 1950 a 1998. Pode-se observar que em 1950 uma parte significativa das margens da ilha estava submersa, somando um perímetro total de 191,5 hectares, enquanto em 1998 era de 216,3 hectares, um aumento de $12,9 \%$, ou seja, 24,8 hectares. A partir de 2015, houve uma redução de $1,8 \%$, que correspondeu a 4,0 hectares da área total. Já na Ilha do Rodeadouro a praia arenosa na sua parte extrema a montante, em 1950 praticamente não existia, contabilizando um perímetro total de 26,3 hectares. A mesma, entretanto, no ano de 1998 tinha um perímetro de 34 hectares, ou seja, um acréscimo de 08 hectares. Após 17 anos, em 2015, a área reduz cerca de 3 hectares $(2,9)$, com um total de 31,1 hectares.

Tais alterações estão relacionadas à dinâmica hidrológica do rio, as oscilações da sua vazão hídrica e regulação exercida pela barragem de Sobradinho. Durante os períodos 
chuvosos na região tanto nas cabeceiras de drenagem a montante como nas de deflúvio a jusante, em que se incluem seus tributários, a vazão do rio extrapola os níveis de seu leito até as áreas naturais de inundação e, a depender do volume precipitacional, inundam toda planície marginal e as ilhas, principalmente nas suas margens extremas e mais estreitas.

No final de 1949, houve uma grande cheia na região, em particular nas proximidades das ilhas, deixando uma boa parte delas submersa. Outras cheias como as de 1983 e 1992, além de inundarem também uma boa parte das ilhas, aumentaram a competência erosiva do rio sobre suas margens, o que associado ao extenso desmatamento ocasionou o assoreamento do seu leito. A carga de material carreado para o rio se acumula nos trechos do leito do canal principal ou de ramificações formando bancos arenosos no topo e cascalhento na base que se desenvolvem como barras de soldamento diagonais as margens das ilhas. Ao longo dos anos essas barras adquirem mais consistência e são colonizadas por vegetação, se consolidando e se agregando as ilhas propriamente ditas. Em contrapartida, cheias recentes, de curta duração, mas intensas, como a de 2004, também ocasionou a perda de terras por erosão nas áreas desprovidas de vegetação ao longo das margens do rio e nas ilhas.

$\mathrm{Na}$ Ilha do Massangano, há indícios de decréscimo lateral por solapamento fluvial e erosão por ravinas interligadas por dutos. Guerra e Mendonça (in Vitte e Guerra, 2004), associam este tipo de erosão às irregularidades do terreno, a retirada da cobertura vegetal e os escoamentos superficial, linear e subsuperficial que rompem a estrutura do solo aprofundando-o e alargando-o, removem o material detrítico aluvionar (areno-argiloso) em direção aos declives e ocasionam o entulhamento do leito do rio.

Sousa et al. (2013), constatou o desmatamento destas atividades nas ilhas com intenso processo erosivo dos solos, colmatação da calha fluvial e perda de terras agricultáveis. Este processo, segundo os mesmos autores, se evidencia com a grande quantidade de espécies exóticas como as algarobeiras (Prosopis juliflora), típicas de condições climáticas mais secas, e o número significativo de gramíneas que comprometem a regeneração natural pela sua agressividade na absorção de água e nutrientes do solo, desestabilizando a encosta fluvial pelo aprofundamento dos sulcos erosivos e a exposição de seu sistema radicular.

\section{CONSIDERAÇÕES FINAIS}

O uso e a ocupação das terras nas ilhas se sucederam de forma concomitante ao crescimento do contexto regional em que faz parte, a região do Alto Submédio São Francisco, e em particular o Polo Irrigado Petrolina-Juazeiro, a partir da década de 1970 com a 
construção da barragem de Sobradinho e, sobretudo na década de 1990 com a fruticultura voltada para exportação e outras regiões do país.

Um destaque foi o crescimento das culturas agrícolas nas ilhas, sobretudo temporárias com proporções bastante significativas de sua área total que alcançou quase $300 \%$. Outro aspecto relevante foi o aumento da ocupação urbana ainda que considerada incipiente nas duas ilhas e a comercial na ilha do Rodeadouro pelo seu forte atrativo turístico.

Este crescimento vem acelerando os impactos ambientais com a degradação da vegetação ciliar e a erosão das terras que alteraram a configuração geomórfica das ilhas e acelerou o processo de assoreamento do leito fluvial.

Este estudo contribui para o diagnostico do uso e ocupação das terras não só das ilhas como pode se estender para toda região do Submédio São Francisco e principalmente neste recorte em que está assentada sua planície poligenética e áreas ribeirinhas, convertendo-se num instrumento importante para a gestão dos seus recursos naturais e um desenvolvimento socioeconômico com mais racionalidade ambiental.

\section{REFERÊNCIAS}

ANA/ GEF/ PNUMA/OEA (a). Diagnóstico Analítico da Bacia do São Francisco e sua Zona Costeira (Subprojeto). Projeto de Gerenciamento Integrado das Atividades Desenvolvidas em Terra na Bacia do São Francisco. Brasília - DF: Agência Nacional de Águas - ANA, Fundo para o Meio Ambiente Mundial - GEF, Programa das Nações eUnidas para o Meio Ambiente - PNUMA, Organização dos Estados Americanos - OEA. 2003.

AQUINO, A. C. de. Ilha do Massangano: dimensões do modo de vida de um povo; a (re)construção do modo de vida e as representações sociais da Ilha do Massangano no Vale do São Francisco. Dissertação (Mestrado em Sociologia). Recife, Universidade Federal de Pernambuco, 2004. 141p.

CAVIEDES, C. N. El Niño in History: Storming through the ages. University Press of Florida, Gainesville, 2001. 275p.

CÓRDOBA, E. S. ; CUNHA, T.J.F. ; SA, I. B. ; GIONGO, V. ; TAURA, T. A. ; OLIVEIRA NETO, M. B. de ; SILVA, M. S. L. da . Uso e ocupação dos solos na margem direita do rio São Francisco, município de Juazeiro-BA. In: CONGRESSO BRASILEIRO DE CIÊNCIA DO SOLO, 2011, Uberlândia. Anais - resumo expandido. Solos nos biomas brasileiros: sustentabilidade e mudanças climáticas: anais. Uberlândia: SBCS: UFU: ICIAG, 2011. 
CUNHA, T.J.F.; SA, I. B. ; TAURA, T. A. ; OLIVEIRA NETO, M. B. ; GIONGO, V. ; ALVAREZ, I. A ; SILVA, M. S. L. . Contribuição à revitalização do rio São Francisco: ocupação e uso do solo em zonas ripárias nos municípios de Petrolina, Lagoa Grande e Santa Maria da Boa Vista. In: XIMENES, L. J. F.. (Org.). Investimento do Banco do Nordeste para o desenvolvimento com preservação ambiental. Fortaleza: BNB, 2011, v. 2, p. 47-72. CUNHA, T.J.F.; SA, I. B. ; GIONGO, V. ; OLIVEIRA NETO, M. B. de ; TAURA, T. A. ; ALVAREZ, I. A. ; SILVA, M. S. L. da ; OlIVEIRA, W. da S. ; LUCENA, A. M. A. de. . Uso atual e quantificação de áreas degradadas na margem do Rio São Francisco no município Santa Maria da Boa Vista-PE. In: REUNIÃO BRASILEIRA DE MANEJO E CONSERVAÇÃO DO SOLO E DA ÁGUA, 2010, Teresina. Anais - resumo expandido. Novos caminhos para a agricultura conservacionista no Brasil. Terezina: Embrapa MeioNorte: Universidade Federal do Piauí, 2010.

FERREIRA, R. V.; DANTAS, M. E.; SHINZATO, E. Origem das Paisagens. In: TORRES, F. S.; PFAltZGRAFT, P. A. S. (orgs.) Geodiversidade do Estado de Pernambuco. Recife: CPRM, 2014. p. 51-70. Disponível em: <http: www.cprm.gov.br>. Acesso em: 07 fevereiro 2015.

FLORENZANO, T. G. Sensoriamento Remoto para Geomorfologia. In: FlORENZANO, T. G. (Org.) Geomorfologia: conceitos e tecnologías atuais. São Paulo: Oficina de Textos, 2008, p. 31-71.

GREGORIO, A. D. Land Cover Classification Systen (LCCS), version2: Classification Concepts and User Manual. FAO Environment and Natural Resources Service Series, N. 8, Rome, 2005. 208p. ( CD-ROM with software).

GUERRA, A. J. T.; MENDONÇA, J. K. S. Erosão dos solos e a Questão Ambiental. In: Reflexões sobre a Geografia Física no Brasil. - (orgs.) Antonio Carlos Vitte e Antônio José Teixeira Guerra. Rio de Janeiro: Ed.Bertrand Brasil. P. 225-256, 2004.

GUERRA, F. Os Caminhos do São Francisco. Secretaria de Educação e Cultura de Pernambuco. Editora: 1974, 110p.

IBGE. Censo Demográfico 2010. Disponível em: <http://www.censo2010. ibge.gov.br>. Acesso em: 05 junho 2016.

IBGE. Censo Demográfico 2000. Disponível em: <http://www.censo2010. ibge.gov.br>. Acesso em: 15 junho 2016.

LIRA, D. R. de. Evolução Geomorfológica e Paleoambiental das Bacias do Riacho do Pontal e GI-8 no Sub-Médio São Francisco. Tese (Doutorado). Recife, Pós-Graduação em Geografia, CFCH, Universidade Federal de Pernambuco, 2014. 234p. 
MMA - Ministério do Meio Ambiente / Secretaria de Recursos Hídricos. Caderno da Região Hidrográfica do São Francisco. Brasília, 2006. 148p.

NASCIMENTO, C. E. de S. A importância das Matas Ciliares do Submédio São Francisco. Petrolina, PE: EMBRAPA-CPATSA, 26p, 2003.

NASCIMENTO, M. G. do.; CORREIA, M. de F.; GONÇALVES, W. A. Eventos Extremos no Submédio São Francisco: uma análise das cheias de 1985 e 2004. 2006. Disponível em: <http://docplayer.com.br/7344134-Eventos-extremos-no-submedio-sao-francisco-umaanalise-das-cheias-de-1985-e-2004.htm>. Acesso em: 10 julho 2016.

OLIVEIRA, Q. Para Dentro e para Fora: o Samba e o Samba de Véio da ilha do Massangano de Petrolina-PE. Historien - Revista de História, n ${ }^{\circ}$, Petrolina, abr./set. 2010.

PEREIRA, A. D. C.; BRAZ, E. R. C. Reservatório de Sobradinho Deplecionamento e Consequências. Anais do VII SBSR, 1993. 211-217p.

RIBEIRO, E. Juazeiro na Esteira do Tempo. 2. Ed. Juazeiro, BA: 2005. 335p.

SECRETARIA MUNICIPAL DE EDUCAÇÃO DE PETROLINA. Regimento escolar da Escola Municipal Santo Antônio, Ilha do Massangano. Setembro de 2015.

SILVA, V. de P. R. da.; MELO, H. de.; TEIXEIRA, A. H. de C.; CAVALCANTI, J. H. F. Impacto do Fenômeno El Niño na Captação de Chuva no Semi-árido do Nordeste do Brasil. Proceedings of the 9th International Rainwater Catchment Systems Conference / Anais da $9^{\mathrm{a}}$ Conferência Internacional sobre Sistemas de Captação de Água de Chuva. Petrolina, Brazil - July 6-9, 1999. Disponível em: <http://www.abcmac.org.br/files/simposio/2simp_vicente_impactodofenomenoelnino. pdf>. Acesso em: 08 setembro 2016.

SOUZA, M. J. N. de; OLIVEIRA, J. G. B. de; LINS, R. C; JATOBÁ, L. Condições Geoambientais do Semi-Árido Brasileiro. Notas e Comunicações de Geografia. Série B, textos didáticos, $\mathrm{n}^{\circ}$ 15. Recife: UFPE/DCG, 1996. 21p.

SOUSA, M. E.; SANTOS FILHO, N. E.; PEREIRA, L. A.; LYRA, L. H. de B.; Monitoramento e caracterização do assoreamento no rio São Francisco nas orlas urbanas de Petrolina-PE e Juazeiro-BA. Revista da Casa da Geografia de Sobral (RCGS), Sobral CE, v. 15, n. 1, 2013, p. 68-20. Disponível em: 〈http:www.uvanet.br/rcgs〉. Acesso em: 20 abril 2016.

SUASSUNA, J. Rio São Francisco: conflito no uso de suas águas. In: FILHO, J. A. Toda a Verdade Sobre a Transposição do Rio São Francisco. Rio de Janeiro: Mauad X, 2008. p. 105-140. 